\section{A PHÝSIS NO CORPUS HIPPOCRATICUM: PROPOSTA DE DOIS TEMAS PARA O MESMO OBJETO}

RESUMO: O conceito de phýsis no Corpus hippocraticum parece ter dois níveis: um mais e outro menos específico. Nas passagens em que o termo phýsis não apresenta qualquer determinante ou adendo, o conceito é menos específico. Ele é mais específico, no entanto, quando o termo leva consigo adjuntos como "do homem", "da criança", "da mulher", etc. Apesar de parecer esta uma questão dicotômica, há razôes para crer que ela possui maior complexidade. Isto nos motivou a apresentar algumas questôes que expõem um espectro bem mais amplo do conceito de phýsis, em detrimento da mera abordagem binária. Para além da complexidade conceitual que ronda a ideia de phýsis, o artigo leva em conta ainda o nível discursivo (talvez mesmo retórico). Neste âmbito, o conceito de phýsis é problematizado a partir da fricção entre enunciação e enunciado.

PALAVRAS-CHAVE: natureza, medicina grega, retórica.

\section{PHYSIS IN THE CORPUS HIPPOCRATICUM: TWO TOPICS FOR THE SAME OBJECT}

\footnotetext{
ABSTRACT: The concept of physis in the Hippocratic corpus seems to have two levels: one of them more and the other less specific. In the passages in which the term phýsis does not show any determiner or addition, the concept is less specific. It is more specific, however, when the term takes complements as "of man", "of child", "of women" etc. Though it seems a dichotomic issue, there are reasons to believe that it bears more complexity. It has instigated us to present some issues
}

\footnotetext{
* Professor Associado da Universidade Federal do Rio de Janeiro (UFRJ)

** Doutora em Letras pela Universidade de São Paulo (USP)
} 
${ }^{1}$ Kühn, V, 507 (De Lacy, II, 362, 5-9; PHP 6,1,

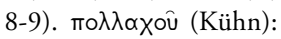

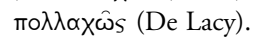

that expose a much wider spectrum of the concept of physis rather than the binary account. Beyond the conceptual complexity which surrounds the idea of physis, this article considers the discursive (perhaps even rhetoric) level. In this account, the concept of physis is examined out of friction between enunciation and enunciated.

KEYWORDS: nature, Greek medicine, rhetoric.

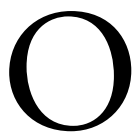
aforismo hipocrático 34 da Segunda Seção traz a

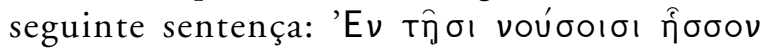

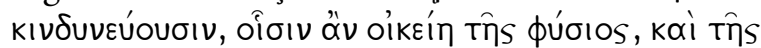

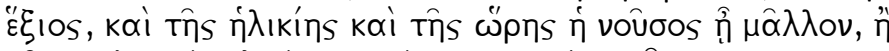

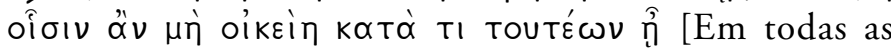
enfermidades corre menos risco aquele cuja enfermidade é própria da natureza, da compleição, da idade, da estação (do ano) do que aqueles para quem a enfermidade não é

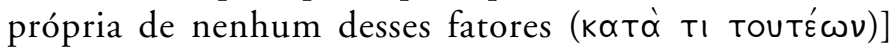
(Kühn, XIX, 529).

Galeno, em seu comentário sobre esse aforismo,

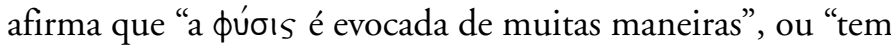
muitos sentidos" (dito em genitivo absoluto: tîs

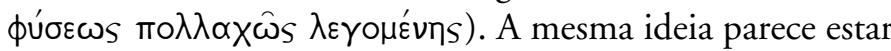
presente também no tratado Sobre as doutrinas de Hipócrates

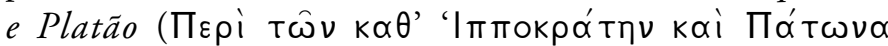

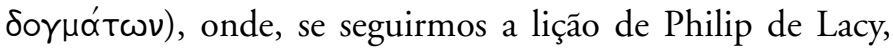

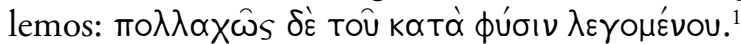

O Comentário ao Aforismo, no entanto, tem uma

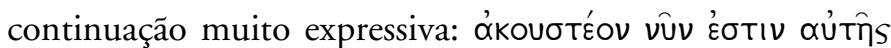

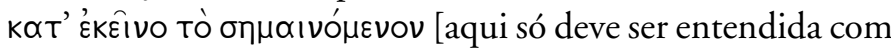
aquele significado], ou seja, pelo on $\mu \alpha ı v o ́ \mu \varepsilon v o v$ do contexto, circunscrito ao dêitico É KÊlvo. Essa continuação do comentário nos autoriza a pensar em uma intenção de especificar semanticamente o vocábulo, assinalando, inclusive, a importância dessa precisão para a própria leitura que Galeno propõe.

A partir dessa relativa plurivocidade e também do

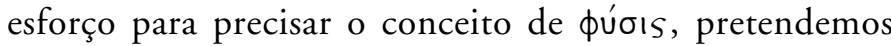
apresentar aqui os resultados mesclados de dois estudos

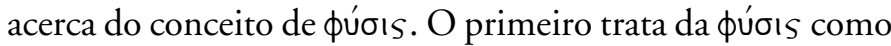
o limiar entre o imanente e o transcendente, em certa 
perspectiva que se pode detectar em epidéixeis médicas do século $\mathrm{V}$ a.C. $\mathrm{O}$ segundo procura verificar textualmente a

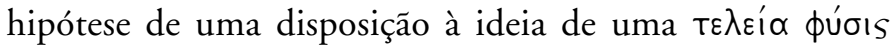

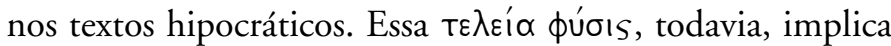
a revisão do posicionamento (i.e., do lugar de fala) do discurso médico relativo à morte, e, se esta faz parte ou não de uma perfeição, em meio a uma linearidade temporal segundo a lógica da corrupção. ${ }^{2}$

De fato, Aristóteles, que mantém seus tratados sobre os animais sempre em dívida com o pensamento hipocrático, ${ }^{3}$ insiste na ideia da geração e da corrupção que dão, aliás, título a um famoso tratado seu sobre os

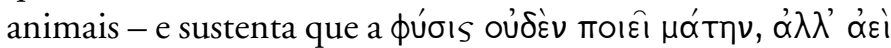

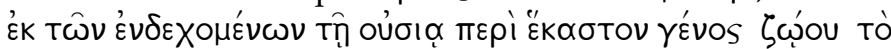

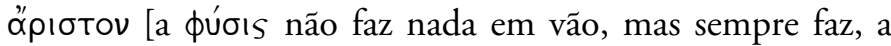
partir do plausível, o melhor conforme a essência de cada gênero de animal.] (De incessu animalium [Пвpi Порвías

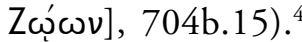

Um texto de Georges Canguilhem escrito para a revista do Centro Católico de Médicos Franceses, em 1972, intitulado "L'idée de nature dans la pensée et la pratique médicales", tem como ponto de partida a citação de uma conhecida passagem do tratado Epidemias VI $(5,1)$ :

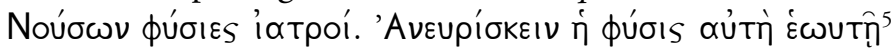

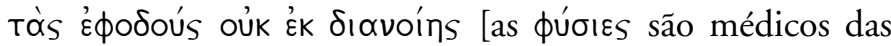
enfermidades. A фúoıs encontra, ela mesma, suas próprias vias e não a partir de um pensamento]. Essa assertiva citada por Canguilhem tem a seguinte continuidade - também

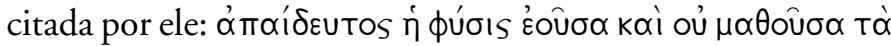

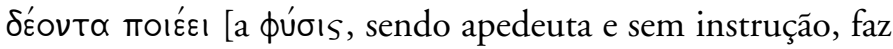

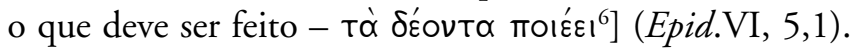

Apesar desse começo e desse mote, Georges Canguilhem atribui exclusivamente a Galeno a ideia de uma

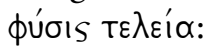

Galeno, que atribui a Hipócrates os conceitos dos quais podemos apenas dizer que são hipocráticos, retomou-os por sua conta e ensinou, ele também, que a natureza é a primeira conservadora da saúde, porque é ela a primeira formadora do organismo. (2005:13)
${ }^{2} \mathrm{O}$ que a difere, ademais, da concepção de $\tau \varepsilon \lambda \varepsilon i ́ a$ фúoıs do tratado $\Pi \varepsilon \rho i$ те́XVпS (v. CAIRUS, 2003).

${ }^{3}$ É conhecida, por exemplo, a extensa citação que Aristóteles (Hist. Anim., 521a12-513a7)

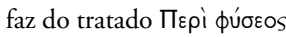

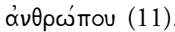

${ }^{4}$ Também em De Partibus

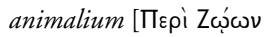

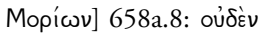

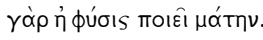

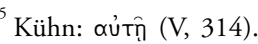

${ }^{6}$ Littré traduz: "faz o que é conveniente”. Essa tradução parece ser fonte para Canguilhem. Preferimos, no entanto, preservar uma ideia que oscila entre a "necessidade como carência" e o sentido deôntico do particípio. 
${ }^{7}$ A passagem do tratado Da dieta (I,15: 'H фúols

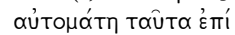

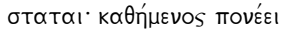

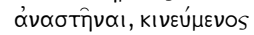

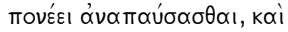

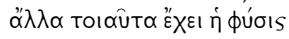
іптрікі̄s), que corrobora com a ideia de algo próximo a uma фúoıs

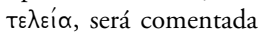
mais adiante.

${ }^{8}$ JOUANNA (1994:532 e 537), JOUANNA

(1988:190).

${ }^{9}$ No tratado, a forma como é apresentada o

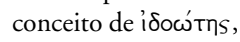
sempre em oposição a iatpós, parece corresponder a uma tentativa de forjar uma analogia da laicidade religiosa com a laicidade médica, criando, assim, por meio dessa analogia, o que talvez tenha consistido no primeiro campo laico da Grécia. Nesse campo, o 'dentro', iatpós, se sustenta

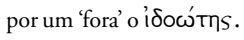

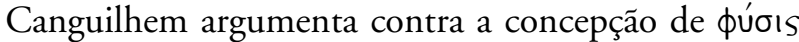

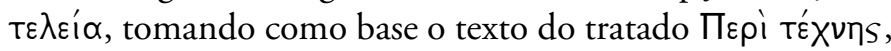

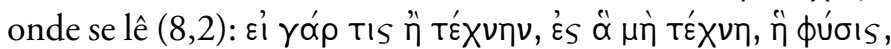

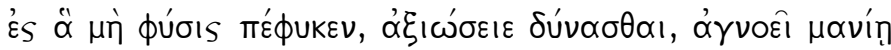

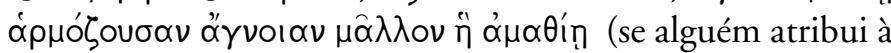

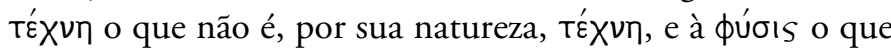
não é, por sua natureza, $\phi$ v́oıs é ignorante de uma ignorância mais de acordo com a $\mu \alpha v^{\prime} \alpha$ do que com uma $\left.\alpha^{\prime} \mu \alpha \theta^{\prime} \alpha\right)$. Do que infere Canguilhem que "onde a natureza cede, a medicina deve renunciar".

Apesar do que se pode apreender pelo tratado Epidemias VI, não há, no Corpus hippocraticum, a concepção de uma natureza propensa à saúde, imaculada e maculável. Essa concepção, para Canguilhem, seria galênica, pois o pensamento hipocrático considera uma "loucura", uma

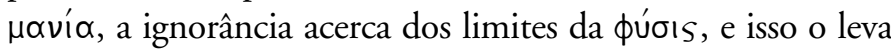
a concluir que "a arte médica é a dialética da natureza" $(2005: 16){ }^{7}$

Os tratados De arte e Epidemias VI são, de fato, próximos cronologicamente, talvez coetâneos, como bem argumenta Jacques Jouanna, ${ }^{8}$ mas consistem em produçōes notadamente diferentes. $\mathrm{O}$ tratado Epidemias VI é - podese afirmar com relativa segurança - obra de um médico itinerante, muito provavelmente discípulo direto do próprio Hipócrates, encarregado, talvez, de observar e relatar casos

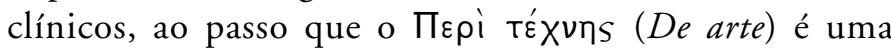
$\dot{\varepsilon} \pi|\delta \varepsilon| \xi \mid s$ argumentativa que tem por meta a constituição e

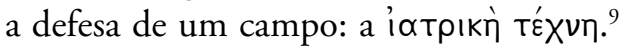

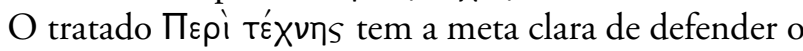
campo dessa T⿱́$\chi \nu \eta$, e, portanto, não se pode esperar que,

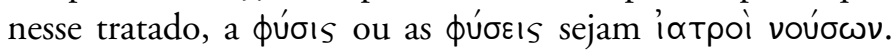
Naquela $\varepsilon \pi \operatorname{m} \delta \varepsilon ı \xi$ Is era necessário afirmar o lugar da medicina, seu lugar como TÉXvin. Não teria cabimento, então, a defesa

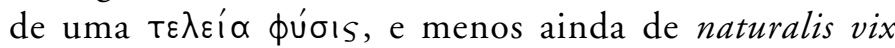
medicatrix (ou uis medicatrix naturae), que foi cientificizada por Walter Bradford Cannon (1871-1945), em 1932, em sua obra The wisdom of the body. Foi também o mesmo Cannon que cientificizou, na medicina, a homeostase, que traduz a definição de saúde de Alcméon de Crotona (B 4 DK), reiterada pelo tratado Da natureza do homem (4). A percepção da saúde como homeostase precede a ideia 
de uma 申úoıs destinada à saúde; a saúde, de resto, não se opõe à morte, mas sim à enfermidade.

A relação antitética direta entre saúde e morte, que está presente no tratado De arte, não pode ser encontrada nos demais tratados mutuamente contemporâneos, que, ao contrário desse mesmo tratado e do Da medicina antiga, não têm o propósito único de instaurar, alicerçar, firmar ou defender a medicina como TÉ Xv $\mathrm{e}$, portanto, como um campo circunscrito unicamente pelas fronteiras de um saber e de seus símbolos.

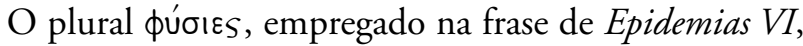
parece assinalar que a фúoıs propensa à saúde - qual um bom selvagem - é aquela que se aproxima mais do homem, que se esparge e que se dissemina entre indivíduos ou coletividades. Assim, essa фúoıs pluralizada toca e repele o homem, mas sua relação com a 申úoıs una e singular é contínua; razão pela qual nem mesmo essa фúoıs ou essas фúoies são domáveis. Galeno, de fato, ao comentar a passagem do tratado Epidemias VI, em que o autor declara

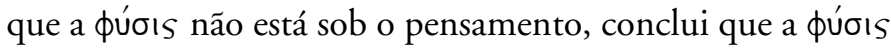
é indomável.

Nas linhas mais gerais do que se poderia depreender como um pensamento hipocrático, se a фúoıs não tem uma propensão à saúde, ao menos tende ao normal, e, se algo a tira de tal rumo, as raízes do desvio estão na ação do homem, e é também a ação do homem que pode restituir-lhe a direção original, mas operando apenas sobre as franjas da фúoıs, que alcançam suave - mas diretamente - a vida.

Canguilhem lembra que "definir o anormal por meio do que é de mais ou de menos é reconhecer o caráter normativo do estado dito 'normal'" (1966:36). Se, por um lado, na medicina hipocrática, ao que se visa não é propriamente ao normal ${ }^{10}$ mas apenas ao saudável; por outro, seus tratados adotam abundantemente o verbo úyıó́દı como princípio normalizador, estabelecendo, dessa forma, uma relação direta - se não sinonímica - entre o padrão de normalidade e a própria saúde. Os tratados humorais, assim como o tratado Da medicina antiga, oferecem copiosos subsídios para o estabelecimento definitivo de um vínculo antitético entre o desequilíbrio e o vómos.
${ }^{10}$ Há, em grego, um adjetivo que expressa a ideia de 'normal': o adjetivo vónıнos. No entanto, esse adjetivo não ocorre nos tratados $D a$ doença sagrada e Ares, águas e lugares. $\mathrm{O}$ adjetivo kolvós, por sua vez, parece só adquirir um significado mais aproximado daquele do vernáculo 'normal' com Dionício de Halicarnaso (Antiguidades romanas, 4,23), no primeiro século antes de Cristo. 
${ }^{11}$ Jouanna (1992:318) escreve sobre a correspondência entre os binômios formados pelos termos vópos e фúoıs, e cultura e natureza, ainda que ressalve que o tratadista nao e um criador dessa ferramenta de análise. O helenista francês adverte, no entanto, que o uso que o tratado faz dessa construção teórica e original, pois, ao contrário dos sofistas, o autor hipocrático matizara essa relação ao descobrir-

lhe as interrelaçôes. A respeito disso, e curioso o sentido do termo vómos na primeira frase do tratado Da geração.
A palavra vónos tal como se a lê no tratado Ares, águas e lugares - ou seja, como o significado de 'costume', 'hábito de um povo' -, aproxima-se consideravelmente da ideia de 'cultura', e indica, desde então, uma preocupação com a relação entre natureza e cultura, cujo dualismo ensejou parâmetros para o pensamento de Lévi-Strauss (1982). ${ }^{11}$ Tal contexto semântico do termo vómos constitui interessante ferramenta para a historicização da interpretação da relação entre natureza e cultura na Antiguidade Clássica.

$\mathrm{O}$ termo vónos expressa, no tratado Ares, águas e lugares, um conceito que está posto em contraposição à $\phi u ́ \sigma ı s$, e que, junto a ela, constitui primeiramente uma relação antitética. Posteriormente, contudo, o vónos recebe o auxílio da mesma фúoıs. Assim, os Macrocéfalos, no décimo

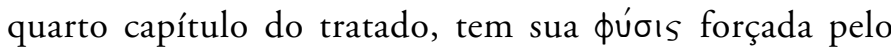
vónos, mas finalmente o vómos gera uma фúoıs que, depois de incorporada, colabora com ele.

O caso dos Macrocéfalos é o do povo que impunha ataduras às cabeças das criancinhas, a fim de que elas ficassem oblongas, por ser tal formato de cabeça valorizado socialmente. Com o tempo, as crianças passam a nascer com a cabeça oblonga e, aos poucos, num prazo mais longo, as crianças vão passando a nascer com a cabeça com o formato não oblongo.

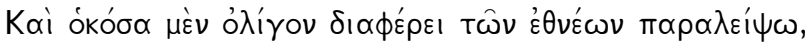

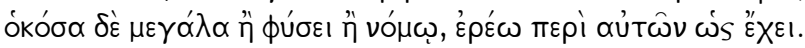

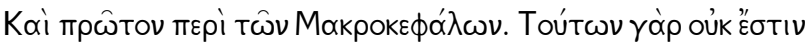

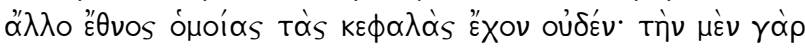

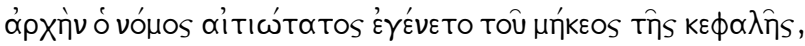

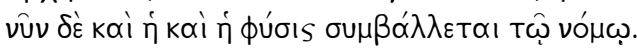

Tudo o que difere pouco nos povos eu deixarei de lado. O que

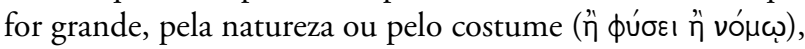
falarei sobre eles, tal como eles são. E primeiramente falarei sobre os Macrocéfalos. Pois não existe nenhum outro povo que tenha as cabeças semelhantes às deles. Quanto à origem disso, o costume (vómos) foi o principal causador da forma alongada de sua cabeça, mas agora a natureza passa a concordar com o costume ( $\dot{\eta} \phi u ́ \sigma \mid s$

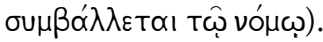


$\mathrm{O}$ autor de Ares, águas e lugares abre-se para a alteridade, percebe e estuda os vómol asiáticos, nota-lhes as peculiaridades e considera suas doenças a partir de três pontos: (1) seus vónol; (2) suas фúбıєs (divididas em dois

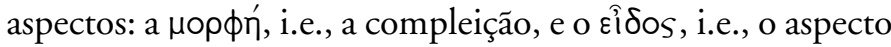
físico), e (3) o entorno.

A natureza é limitadamente influenciável pelo vómos, e é dentro desse limite que o médico opera. Seu instrumental - ou arsenal - para lidar com a фúoıs é, portanto, oriundo

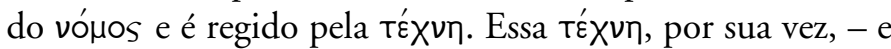

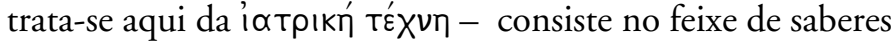
necessários para operar duas ferramentas: o фópuณkov e a

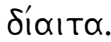

A diaita configura-se como um instrumento desse vónos com o qual o homem, e especialmente o médico,

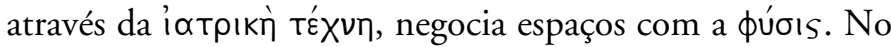
tratado $\mathrm{Da}$ dieta, essa negociação paira sobre a construção retórica do conceito de saúde - não como oposição à doença ou como ausência dela, mas pretendendo-se um sistema perfeito, que, no caso específico deste tratado, exclui a doença, colocando-a no lugar da anomia -, de maneira a permitir que o médico tratadista justifique retoricamente a sua tese e seu héurema, como se lê no terceiro livro do $D a$ dieta (69):

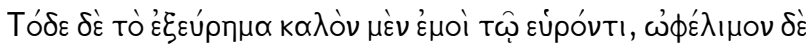

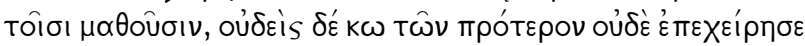

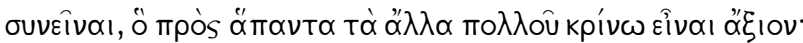

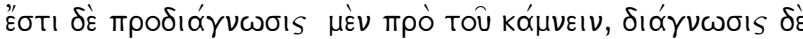

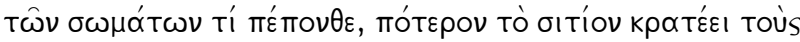

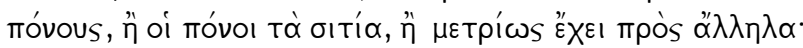

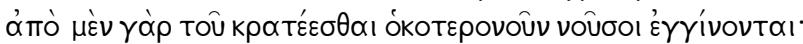

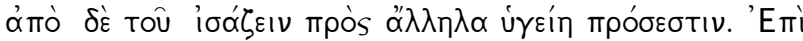

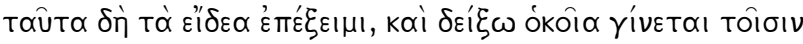

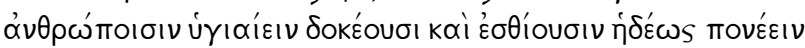

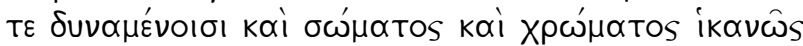
हैXOUช।V.

Este descobrimento é belo para mim, que o descobri, e útil para os que aprendem, pois ninguém tentou entendê-lo anteriormente, algo que, mais que qualquer outra coisa, julgo digno de que se entenda. É a prodiagnose antes de adoecer, a diagnose dos 
corpos, a saber, quais suas afecções, se o alimento excede os exercícios ou se os exercícios, o alimento, ou se há um equilíbrio entre os dois, ou do equilíbrio entre ambos. Pois do domínio de qualquer um ocorrem as doenças. E do equilíbrio entre eles provém a saúde. Então, irei detalhar essas condições e mostrarei como é para os homens que parecem estar saudáveis e comem com prazer e se exercitam como podem, e têm corpo e compleição adequada.

A prodiagnose desse autor esquematiza-se numa base positiva pautada no conceito de saúde. Isso fica evidente

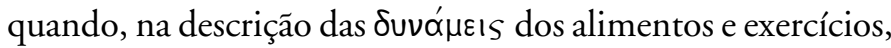
o ponto central é o efeito que a combinação tem no homem saudável, e considera apenas desequilíbrios da ordem dos sintomas leves (para citar alguns, diarreias, azias, disúrias, febres brandas, corizas etc.), prévios à doença. Nesse sentido, a doença ficaria situada além do ponto extremo do seu esquema fechado, reafirmando o caráter higiênico da sua obra. Já a dieta dos doentes ocupa o centro dos tratados Das afecçôes e Da dieta nas doenças agudas, o que reitera o caráter da obra.

$\mathrm{O}$ tratado Da dieta considera fundamental a tensão e complementação entre os opostos, cujo maior exemplo talvez seja a dicotomia formada por vónos e фúøıs, que, à primeira vista, parece remeter a um argumento de boa tessitura retórica de uma oposição entre humano e divino.

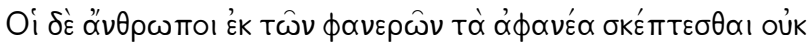

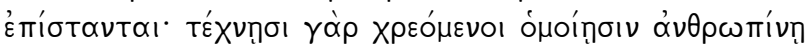

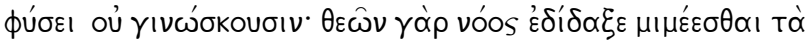

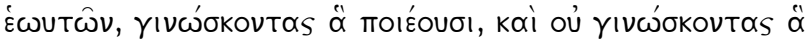

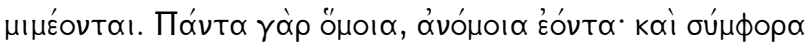

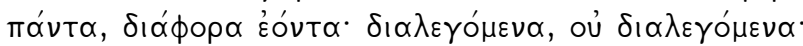

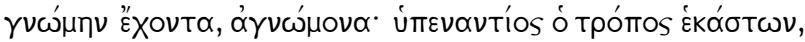

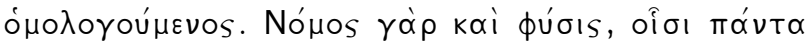

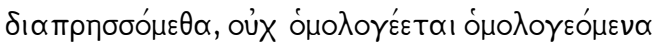

Os homens não sabem observar o invisível a partir do visível. Pois utilizando tékhnai semelhantes à phýsis humana, não o sabem. Pois o pensamento dos deuses ensinou-os a imitar o que lhes é próprio, e, conhecendo o que fazem, não conhecem o que imitam. Pois tudo é semelhante sendo dissemelhante, concorda não 
concordando, possui razão, não tendo razão. Oposta é a direção de cada uma das coisas, completando-se entre si. Pois vónos e фúoıs, através dos quais obtemos tudo, não concordam concordando. (De dieta, 1, 11)

O Da dieta faz parte dos tratados hipocráticos nos quais se nota com clareza irrefutável a instrumentalização do saber retórico. O capítulo quarto do primeiro livro do tratado, num imbricado jogo de oposições, aponta uma фúoıs harmônica, para a qual os opostos integram um todo, em complementação, e um vónos que fraciona, em opostos, o processo natural e valora suas partes, umas em relação às outras, e, à guisa de conclusão desse intrigante discurso, o tratadista propõe o último par antitético, formado,

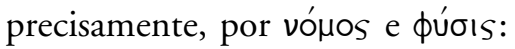

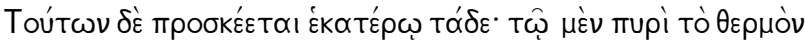

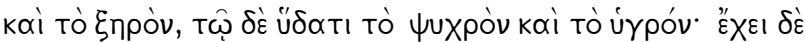

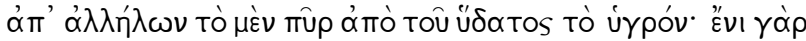

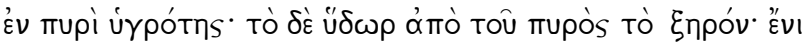

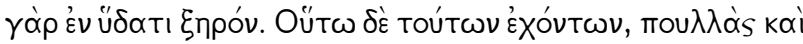

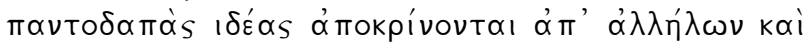

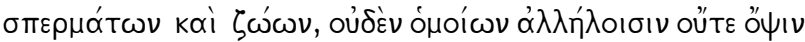

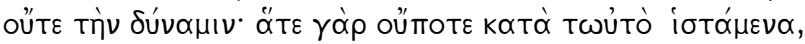

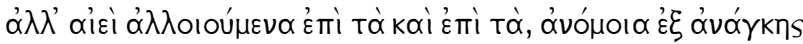

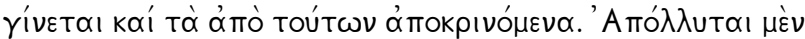

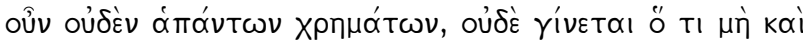

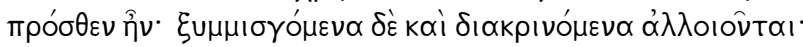

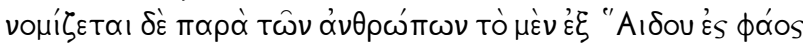

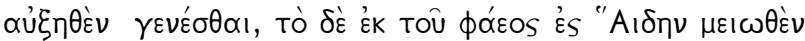

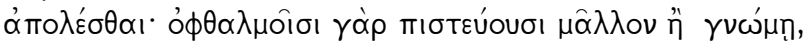

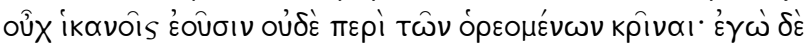

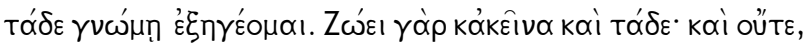

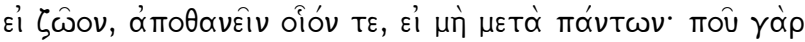

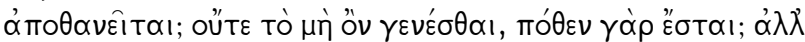

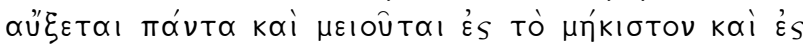

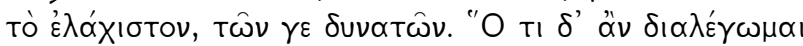

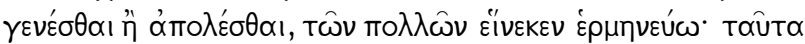

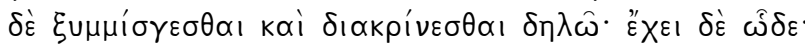

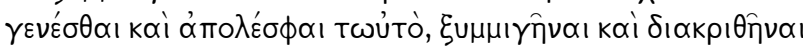

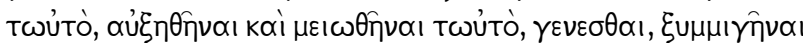

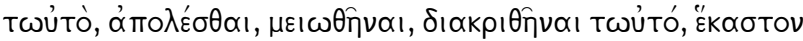

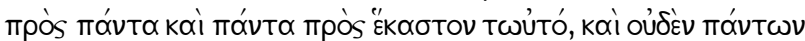

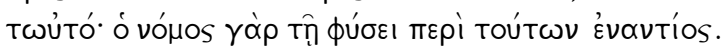

${ }^{12}$ A conclusão desse raciocínio faz crer que o adjetivo óvouoı $\propto$ já faz ressoar a ideia de óvouía. A dissemelhança, de fato, é algo da ordem algo ligado à categoria nômica.

${ }^{13}$ Segue-se aqui a lição de Littré - $\pi \alpha \rho \alpha \grave{~} \tau \hat{\nu} \nu$ $\dot{\alpha} v \theta \rho \omega ́ \pi \omega \nu$ - (seguindo uma emenda de altera manu - séc. XIV - ao manuscrito Parisinus 2142 - séc.X), em detrimento da de Jones -

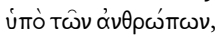
fundamentada no Parisinu2155.

${ }^{14}$ Essa passagem parece inverter o binômio já clássico à época deste autor. Aqui vale referir o episódio narrado por Heródoto no livro I, o de Giges ante o pedido do soberano Candaules de ver a rainha da Lídia, sua mulher, nua, para que acreditasse que era ela a mulher mais bela de todas. A propósito desse projeto de Candaules, Heródoto cita o adágio, segundo o qual "

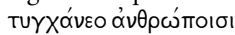

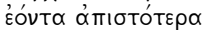
ỏ $\phi \alpha \lambda \mu \omega \hat{v}$ " (História, 1.8.3), "pois acontece de serem para os homens os ouvidos menos confiáveis do que os olhos". Heráclito (fr.101a), citado por Políbio (Polib. XII 27), corrobora esse dito:

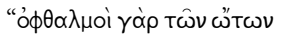

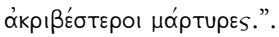
Neste tratado, apõe-se ao díptico formado por olhos e ouvidos a $\gamma \nu \omega ́ \mu \eta$, termo relacionado, a um só tempo, com a atividade intelectiva e a de inserção numa tradição. Seguindo esses passos, o pensamento 
relacionado à tradiçãao impōe-se como o terceiro e mais importante elemento na constituição do conhecimento que se sabe devedor da míotıs.
A cada um deles se designa o seguinte: ao fogo, o seco e o quente; à água, o úmido e o frio. E cada um tem do outro: o fogo tem da água o úmido, pois há no fogo umidade; e a água tem do fogo o seco, pois há na água secura. Sendo assim, em muitas e em variadas formas, secretam-se uns dos outros, as sementes e os animais, e nada têm entre si de semelhante, nem em aspecto nem em propriedade. Uma vez que eles nunca ficam em si, mas estão sempre mudando para um ou para outro, por necessidade, torna-se também dissemelhante ${ }^{12} \mathrm{o}$ que é secretado deles. Portanto, de todas as coisas, nada perece nem nasce nada que não havia antes: o que se mistura e o que se separa muda. No entanto, entre os homens ${ }^{13}$ há a crença de que o que nasce cresce do Hades para a luz, e de o que perece míngua da luz para o Hades. Acreditam, pois, mais nos seus olhos do que no juízo, os quais não são capazes de julgar sequer o que veem. Mas eu explico essas coisas por meio do juízo: ${ }^{14}$ pois são animais tanto aqueles quanto estes: se é vivo, não pode haver morte, a não ser com o conjunto de todas as coisas, pois como morreria? Nem o que não existe nasceria, pois, de onde viria? Mas tudo cresce e tudo míngua para o máximo e para o mínimo das possibilidades. O que eu chamo de nascer ou perecer, por causa da plebe, assim interpreto, mas explicito [agora] que essas coisas são misturar-se e separar-se. Pois é assim: nascer e perecer é a mesma coisa; misturar-se e separar-se é a mesma coisa; aumentar e diminuir é a mesma coisa; nascer e misturar-se éa mesma coisa; morrer e separar-se éa mesma coisa, cada um em relação a todos e todos em relação a cada um, e nenhum deles é o mesmo; pois o vóuos é contrário à фúoıs no que concerne a essas coisas. (De dieta, 1,4)

A distinção proposta pelo tratado entre os pares antitéticos, a partir da própria oposição entre фúoıs e vónos, tem também um caráter hermenêutico - sugerido, de resto, pelo próprio verbo $\varepsilon \rho \mu \varepsilon v \varepsilon u ́ \omega ~-$, característico, ele próprio, do universo do vónos. Por esse viés, a separação é uma hermenêutica do todo, e, talvez seja útil dizer, assim se entendia o método hipocrático; ao menos, desde a conhecida definição platônica de $\mu$ étooos (Fedro, 270c) às categorizações aristotélicas.

A catalogação, uma forma de categorização que se nota - ao menos - desde Homero, dá forma e conteúdo à descrição dos alimentos no tratado $\mathrm{Da}$ dieta. $\mathrm{O}$ critério de categorização tem por alicerce as dynámeis, e alinha-se à ideia dessa

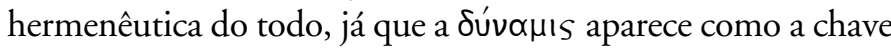
de leitura para a compreensão da phýsis como um todo. 


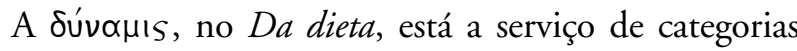
que se coadunam com as qualidades naturais, ou seja, as

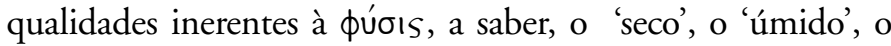
'quente', o 'frio' e outras mais específicas, como 'picante', 'adstringente' etc., todas notadas a partir de uma percepção, de uma đïoӨnoıs. Essas qualidades naturais, por sua vez, são

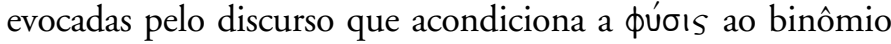
formado por 'fogo' e 'água'. A observação, a descrição e a prescrição do processamento dos alimentos integram a ação - sempre de base empírica - do médico e geram uma ação quase dialética - ou mesmo dialética - na elaboração, organização e formulação de conceitos. O conhecimento alegado das causas e da organização do microcosmos em relação ao macrocosmos ( $D a$ dieta, 1,10 et sq.) e a aplicação dessa ordem física aos elementos que estão ao alcance do homem mediante uma T⿱㇒́x $\backslash \eta \eta$ própria fundamenta discursivamente a autoridade do médico e legitima o seu lugar de fala.

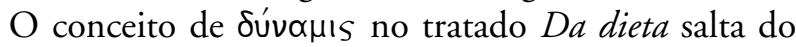
nível do enunciado para o da enunciação e suas formas. No

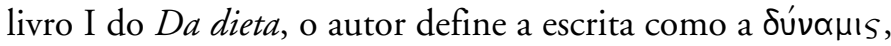
por sua potencialidade mnemônica, num raciocínio que se aproxima da escrita-phármakon do Fedro platônico (274b278b). Para além disso, refletir sobre a própria escrita e compará-la com a medicina e com as outras Téxvaı ( $D a$ dieta, 1,23) mostra com clareza a pretensão do lugar do

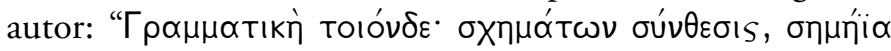

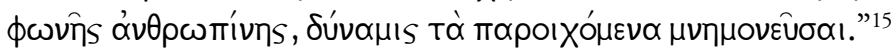
("A escrita é assim: uma combinação de figuras, sinais da voz humana, a capacidade de relembrar os feitos passados").

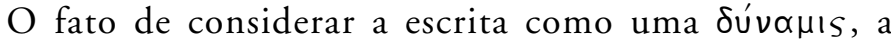
propriedade ativa que é passível de observação e de manipulação - o que é, de certa forma, o objeto da sua obra -, denota sua atitude relativa ao seu projeto de composição do próprio tratado.

Ora, se no capítulo 10 do livro I, ele afirma que " $\varepsilon v i ́$

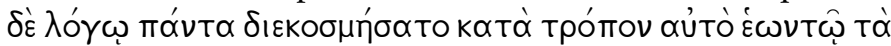

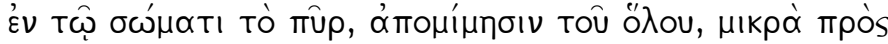

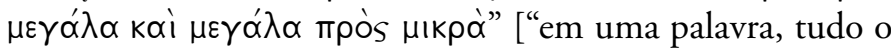
fogo arrumou no próprio corpo por si mesmo, em imitação do todo, pequeno com grande e grande com pequeno"], e, logo depois, exemplifica a sua assertiva a partir do 
${ }^{16}$ Estrabão (XI,8), ao enumerar os $\pi \alpha \rho \alpha ́ \delta \pi \xi \alpha$ dos povos barbaros, cita um povo do Cáucaso que tinha o mesmo hábito: tıvàs $\delta$ '

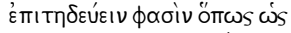

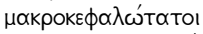

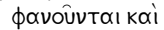

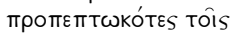

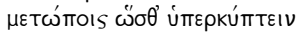
$\tau \hat{\omega} v \gamma \varepsilon v \varepsilon i \omega \omega v$ [dizem que alguns se empenham para parecer macrocafalos, desenvolvendo a fronte até que essa ultrapasse o queixo]. Observa-se, nesse trecho, uma oposição entre certa "realidade" e uma aparência, expressa pelo verbo $\phi \alpha \nu \omega \tilde{\text {. }}$

Jouanna (1996:305) recorda que a dilatação da cabeça foi atestado pela arqueologia no Chipre e na

Lícia, e foi um costume difundido na Europa medieval, especialmente na Gália.

${ }^{17}$ AAL, 14: Toû dé Xpóvou

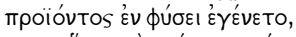

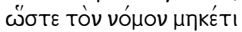

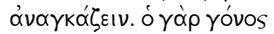

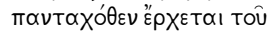

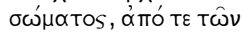

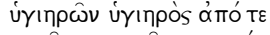

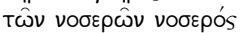

[como o passar do tempo, (a forma) passa à фúoıs, ainda que o vómos não a force mais. Pois a semente geradora provém de todas as partes do corpo: das partes sãs, vêm o são, e, das partes doentes, o doente]. A tese da pangenética é central no tratado Da geração (1):

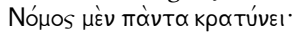

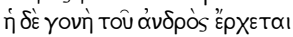

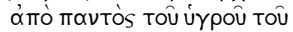

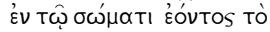

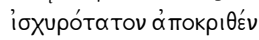
[o vónos governa tudo: a semente vem de todo o líquido que o corpo contém, havendo se separado deste sempre a parte mais forte].

O tratado Da doença sagrada parece estar de funcionamento do corpo humano, indo em direção às tékhnai dominadas pelo homem, culminando na passagem acima citada, no capítulo 23, acreditamos ser plausível a ideia de o nosso autor - enquanto um ietrós que verte seu conhecimento na escrita - ter concebido a sua obra (pelo

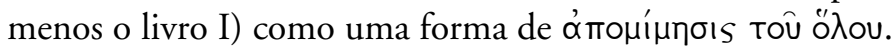
O capítulo 15, nesse sentido, ilustra bem essa ideia:

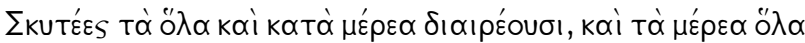

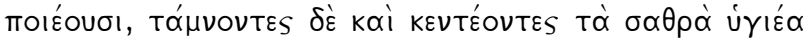

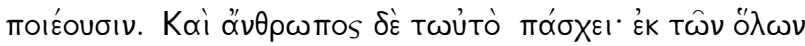

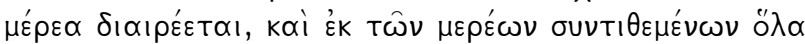

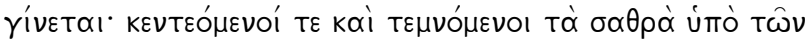

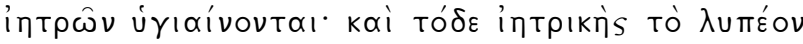

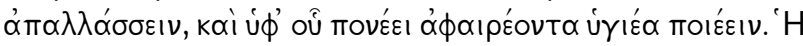

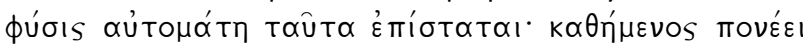

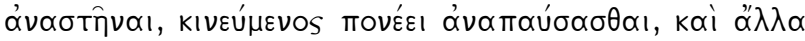

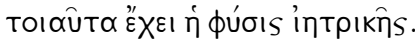

Os curtidores dividem o inteiro em partes e tornam as partes coisas inteiras. Cortando e picando tornam são o que está putrefato. Com o homem se passa o mesmo: do inteiro divide-se em partes e, compondo-se das partes, se torna inteiro. Picados e cortados pelos médicos, tornam-se sãos. E isto é [próprio] da medicina, afastar o que provoca dor, e, ao fazer com que se afaste o sofrimento, tornar são. A phýsis por si mesma sabe isto: levantar o doente que está sentado e fazer repousar o doente que está em movimento, e outras coisas assim a phýsis tem da medicina.

Entre o dizer, o dito e a práxis, o tratado Da dieta

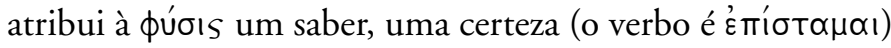
da qual ela, a фúoıs, é senhora por si, autômata. Esse saber é o de indicar, sem equívoco, o que o doente deve fazer. Com isso, a фúoıs partilha do domínio da medicina, por um certo saber relativo à ação. Essa é uma concepção de фúoıs, decerto, bem próxima à uis medicatrix naturae. A

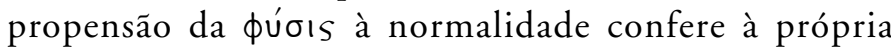
normalidade um caráter natural; naturalizando, assim, por extensão, um êthos ou mesmo um nómos.

A questão da naturalização do êthos em relação a certa humanização da фúoıs ocupará um lugar central na discussão acerca da genética. 
A genética é, de fato, um tema precioso no Corpus hippocraticum e pode-se mesmo notar alguma divergência sobre ela, sobretudo em tradados de épocas distintas. $\mathrm{O}$ tratado Ares, águas e lugares traz, no entanto, uma das mais completas descrições do que poderia ser uma genética hipocrática.

Jackie Pigeaud (1997, p. 9), acerca desse aspecto do tratado Ares, águas e lugares, indica que, nessa relação um tanto complexa, há um certo lamarckismo avant-la-lettre. As expressões "conservação das aquisiçōes" e "transmissão das modificações adquiridas", tão características do pensamento de Lamarck, são muito aplicáveis à tese de hereditariedade do tratado:

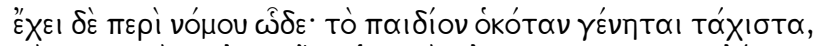

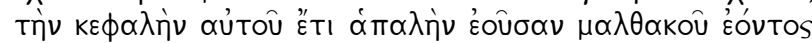

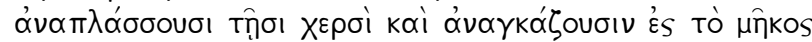

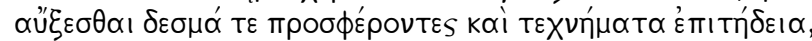

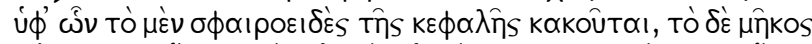

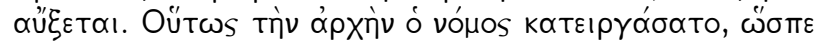

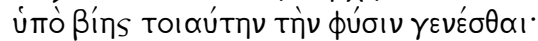

Sobre [tal] nómos, é assim: assim que nasce a criancinha, moldam com as mãos sua cabeça ainda tenra, enquanto está mole, e forçamna para aumentar o alongamento, valendo-se de atadura ${ }^{16} \mathrm{e} \mathrm{de}$

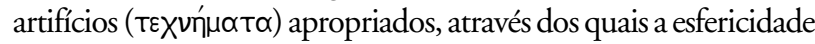
da cabeça se altera e o alongamento aumenta. Assim, na origem, o costume se cumpre, de sorte que tal natureza está submetida à força violenta (iтrò ßíns).

A ßía, o vigor da violência interventora do homem, pode fazer com que um elemento do vómos seja incorporado

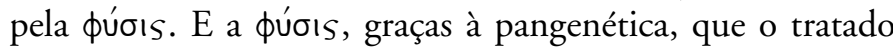
Ares, águas e lugares ${ }^{17}$ defende e ao qual o tratado $\mathrm{Da}$ doença sagrada alude, atinge os descendentes.

A ideia de uma фúoıs que pode ser influenciada pelo homem não apenas humaniza o corpo, mas principalmente denuncia o lato poder que o homem pode exercer sobre sua própria natureza. Nesse sentido, o texto do tratado Ares, águas e lugares pode parecer, tendo dado alguns passos nos argumentos laicizadores da doença, contradizê-los naquilo que Pigeaud considera que lhes é mais fundamental. acordo em tudo com essa ideia, por coincidir quase textualmente ( $\mathrm{Da}$ doença sagrada, 2) com o tratado Ares, águas e lugares. $\mathrm{O}$ tratado Da geração, contudo, apresenta um vónos proveniente da фúøıs. 
Jackie Pigeaud acrescenta ao debate acerca do tratado Da doença sagrada nova perspectiva, que desloca o conceito de aítía nessa discussão. Entendida tal como Lloyd (1990, p. 61 ss) a considera, a oitía são as epícrises patológicas referidas no tratado. De fato, é com esse sentido que vemos o termo ser empregado frequentemente no Corpus hippocraticum. As aitíaı, que são conduzidas do universo divino para o universo da $\phi$ úoıs, levam consigo toda sua carga de responsabilidade. A фúoıs, no entanto, não se a pode responsabilizar: sua matéria não é permeável - apenas

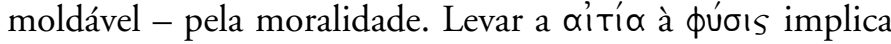
desculpabilizar a doença. Essa empresa de desculpabilização serviu, evidentemente, se muito, apenas ao seu propósito imediato, e mesmo Tucídides (II, 54) é sutilmente transversal na tessitura discursiva da relação entre óvouía e vóoos.

Para Pigeaud (1987, passim), essa desculpabilização da doença se refere sobretudo ao homem, que, como indica o tratado, não mais poderia controlar parcialmente a фúoıs. Idealmente, o controle de uma parte da фúoıs implicaria seu controle total, e pode-se esperar, nesse contexto específico, certa dificuldade para conceber-se um poder transcendental que não tivesse contornos mais ou menos nítidos, especialmente em suas fronteiras com natureza. Apesar disso, é nesse mesmo contexto que se construiu um discurso em que os limites do kpótos da фúoıs, da sua força de domínio, são postos à prova. Colocá-los à prova, todavia, não consistia em sacrilégio, porquanto a 申úoıs não se afigura precisamente como um espaço divino, e sim como um campo neutro que se estende até as bordas do Panteão, onde os deuses intervêm e onde o homem já não pode mais atuar. Eis um passo do tratado Da doença sagrada (4 Jones) que ilustra bem esse ponto de vista:

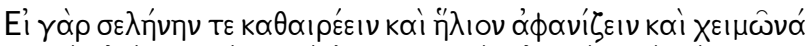

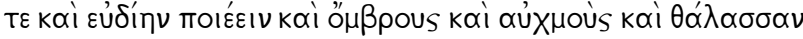

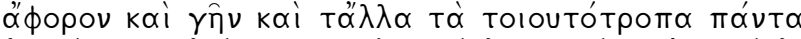

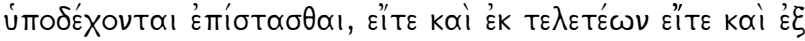

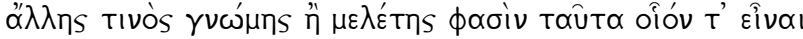

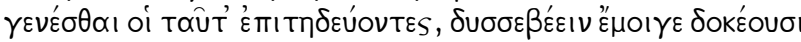

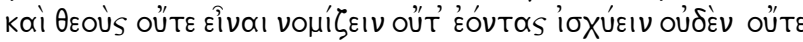

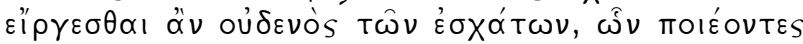

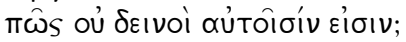


Pois se prometem saber baixar a lua, ocultar o sol, produzir o inverno e o bom tempo, a tempestade e a seca, e tornar o mar estéril e também a terra, e fazer tantas outras coisas semelhantes, os que praticam isso dizem que são capazes de fazer acontecer essas coisas, seja através de ritos, seja através de qualquer outra técnica ou prática; então, a mim, eles parecem ser ímpios nem acreditar existirem deuses, nem, existindo, que tenham algum poder, nem que poderiam impedir nenhum dos atos extremos. Praticando tais atos, como não seriam terríveis aos próprios deuses?

O poder-saber a que faz referência este excerto do tratado ameaçaria os próprios deuses, pois o homem estaria rompendo uma fronteira entre o divino e o humano. É necessário, pois, que o homem se mantenha distante da

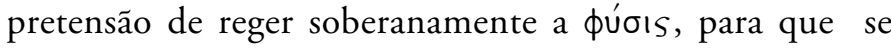
estabeleça outra forma de convivência com essa фúoıs. Não se trata de abdicar de dominar a natureza, projeto tão antigo quanto a própria civilização; mas de dominá-la como um Odisseu, não como um Agamemnon ou como um Ájax. $\mathrm{Ou}$, em outras palavras, é necessário engendrar $\mu \eta \chi \propto \alpha{ }^{\prime} i^{\prime}$ capazes de ocupar o lugar do poder que, ao menos na retórica do tratado, fora exercido de maneira direta ou por intervenção de algum deus - como para aqueles que esperavam um deus ex natura no lugar de um deus ex machina.

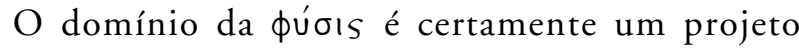
inerentemente humano, mas alguns tratados do Corpus hippocraticum parecem argumentar que, para dar prosseguimento a esse projeto, seria necessário um conhecimento claro dos limites de que fala o tratado $D e$ arte $(8,3)$, onde se lê que o médico deve saber reconhecer quando "o mal que o homem sofre é mais forte do que os instrumentos (op $p \gamma \alpha v \alpha$ ) da medicina". Em outros termos, uma conjuntura do vómos engendra uma té $\chi v \eta$, que é um conjunto de saberes que gera öprava, com os quais o homem pode por à prova seus limites de interferência na фúoıs, atribuindo invariavelmente à transcendência o que está mais para além desses limites.

Como foi dito, Jackie Pigeaud (loc.cit.) vê, no tratado Da doença sagrada, uma desculpabilização do homem. Tal desculpabilização se encontra no contexto dos novos limites 
que certas vertentes do pensamento grego do século $\mathrm{V}$ a.C. impuseram ao sagrado. A compensação da perda de poder sobre a фúoıs é o desencargo moral. A ideia de Pigeaud acerca da desculpabilização da enfermidade é o argumento central de sua teoria sobre o tratado Da doença sagrada, e tal perspectiva inovadora exige novas abordagens.

A contradição que poderia ser encontrada entre essa desculpabilização que Pigeaud defende haver no tratado $D a$

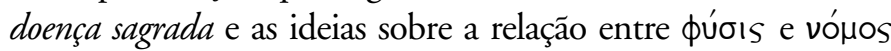
no tratado Ares, águas e lugares pode ser minimizada se considerados os limites do poder da ação do vónos sobre a

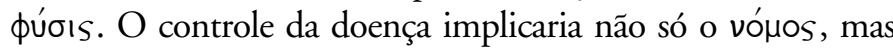
também o domínio dos ares, das águas, e, enfim, dos lugares.

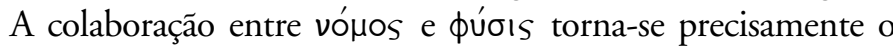
instrumental do médico, que adota, como seu procedimento

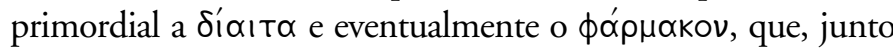
com as manobras médicas, formam os öpyava de que trata o De arte.

Há, em vários textos hipocráticos - como no Ares, águas e lugares ou no Da doença sagrada ou ainda no $D a$

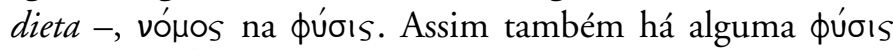

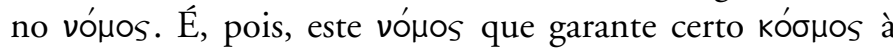

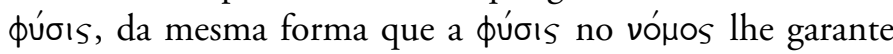
sua plenitude humana.

É certo que a фúoıs, ao menos no Corpus hippocraticum - e quiçá em toda a literatura grega, ao menos do século V a.C. -, é bidimensionada (ou fendida?) em geral e particular, onde a particular é expressa por adjuntos adnominais como:

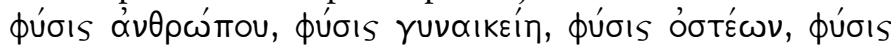
maı́íou (todos títulos de textos hipocráticos). A referência ao caráter particular da фúoıs efetivamente não restringe a atuação da фúols, mas reproduz em escala menor e

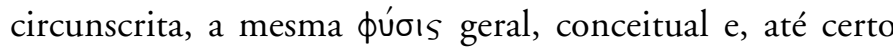
ponto, abstrata, sem, contudo, reduzir sua potencialidade,

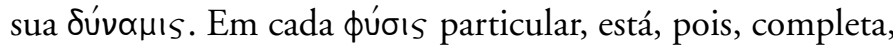
mas reduzida (ao limite físico, corpóreo), toda a фúoıs geral, que prescinde de adjuntos adnominais.

Quando lhe faz par o vómos, fá-lo no diapasão do coletivo, que, nesse caso especial, é o geral do particular. Não é frequente, todavia, um vónos que lhe faça oposição, o que não diz muito, porque esta oposição sequer é tão 
corrente textualmente. A única ocorrência, de resto, de vómos no tratado De natura ossium $(13,10)$, nota-se-lhe o sentido de 'partição', herdado do verbo vé $\mu \omega$.

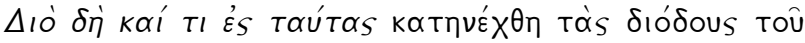

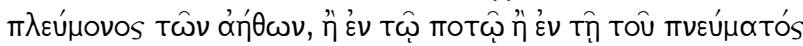

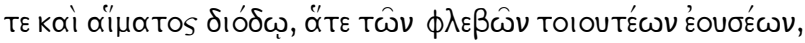

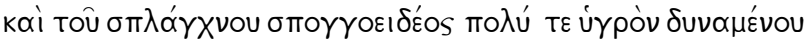

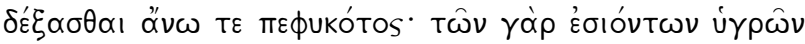

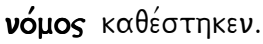

Por isso, também é introduzido algo de incomum nessas vias do pulmão, seja pela bebida, seja pela passagem do fôlego e do sangue, sendo assim as veias, sendo esponjosa a víscera, capaz de absorver muito líquido e, por natureza, [localizada] na parte superior; pois [ali] se situa a partilha dos líquidos que entram.

Nos extensos tratados De natura muliebri e De natura pueri não há nenhuma ocorrência do termo vómos, mas, no Da natura hominis, há não só muitas ocorrências de vómos, como há também copiosas correlações entre as expressões

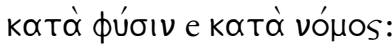

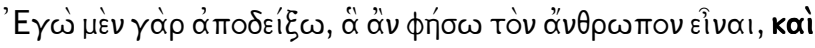

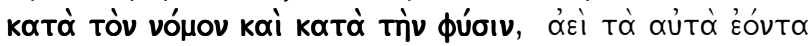

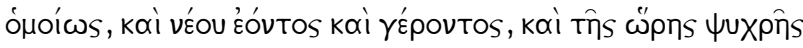

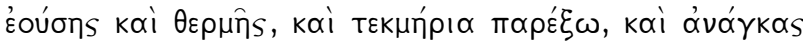

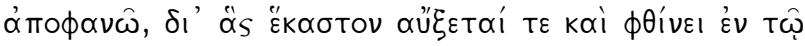

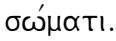

$\mathrm{Eu}$, por minha vez, demonstrarei que as substâncias que afirmarei constituírem o homem, quanto à natureza e quanto ao costume

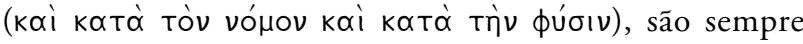
uniformemente as mesmas, e sendo novo ou velho, quer estando na estação fria ou na quente. Apresentarei provas e revelarei necessidades graças às quais cada substância aumenta e se extingue no corpo. (De natura hominis, 2)

É significativo que as referências ao conceito de vónov - expressas por qualquer de seus cognatos - são quantitativamente proporcionais à generalidade do sentido

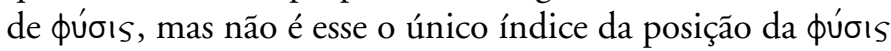


no espectro semântico em torno do eixo (ou do vetor) que se propõe entre a natureza mais ou menos tangível pelo homem e a esfera do vónov, completamente dependente de

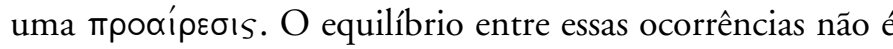
a única sinalização textual da presença de tal dicotomia, mas, para além desse fato - em nada supreendente -, nota-se

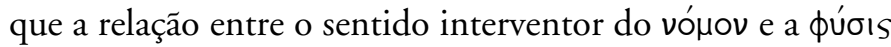
não é exatamente antitético, e não só por causa do princípio sublinear naturalis vix medicatrix.

A фúoıs hipocrática, portanto, não pode ser compreendida como algo espontâneo, conforme a usual interpretação do termo. A ideia de uma фúoıs que não depende da ação do homem é ameaçada pela necessária matização da própria фúoıs, a partir de sua tangibilidade pela deliberação humana, ou seja, por força da mpooíıбıs.

Nos textos que examinamos, há uma clara ideia de que o campo que se desfralda entre o território exclusivamente divino e a terra dos бıтофóy $\sigma$ - para usar uma expressão

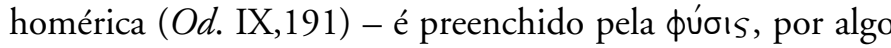
que é gerado pelos deuses e pode ser parcialmente gerido pelos homens. Essa geração divina - possível gérmen do

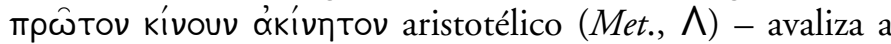
expectativa de uma $\tau \varepsilon \lambda \varepsilon i ́ \alpha$ фúoıs quase edênica, mas que se

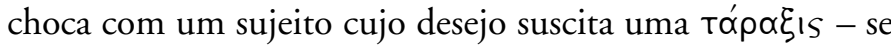
seguirmos o percurso epicurista -, cabendo ao homem a deliberação de realocar suas ações, numa negociação marcial em que não faltam as armas retóricas. Assim, a relativização

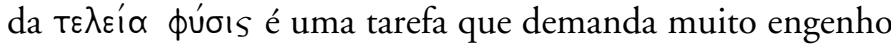
discursivo, mas faz parte também de um contexto de afirmação (ou fixação) de um campo específico de um saber

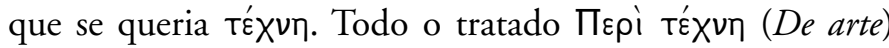
não é menos do que uma epídeixis que reivindica o status

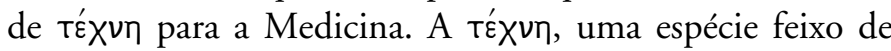
conhecimentos sistematizadores das $\mu \eta \chi \propto v \alpha$ í, algo, portanto da esfera da operacionalidade humana, da instrumentalização para um embate pela dilatação dos limites da atuação humana no terreno da 申úoıs. 


\section{REFERÊNCIAS}

ARISTOTE. De incessu animalium. Paris: Les Belles Lettres, 1987.

CAIRUS, Henrique Fortuna. O vocabulário fisiológico do tratado hipocrático Da natureza do homem. Dissertação de Mestrado em Letras Clássicas. Rio de Janeiro: Faculdade de Letras da Universidade Federal do Rio de Janeiro, 1994.

. Os limtes do sagrado na nosologia hipocrática. Tese de Doutorado em Letras Clássicas. Rio de Janeiro: Faculdade de Letras da Universidade Federal do Rio de Janeiro, 1999.

"A alma do corpo e o corpo da alma entre os gregos antigos". In: Calíope Presença clássica, v. 15, p.72-90, 2006.

; RIBEIRO Júnior, Wilson A. Textos hipocráticos: o doente, o médico, a doença. Rio de Janeiro: Ed. Fiocruz, 2005.

, ALSINA, J. A alimentação na dieta hipocrática. Clássica, v. 20, p. 212, 2010.

CANGUILHEM, G. Escritos sobre a medicina. Rio de Janeiro: Forense, 2005.

. O normal e o patológico. Trad. Maria Thereza Redig de Carvalho Barrocas. Rio de Janeiro: Forense, 1990.

CANNON, W. B. The wisdom of the body. New York: W. W. Norton \& Co., 1932.

GALIEN. Galeni opera omnia. Ed. Karl Gottlob Kühn. Leipzig: Car. Cnoblochii, 1821-1833. (http://www.biusante. parisdescartes.fr/histmed/medica/cote?45674)

DESCOLA, P., PALSSON, G. (ed.). Nature and society: Anthropological perspectives. London: Routledge, 1995.

HEINIMANN, F. Nomos und physis: Herkunft und Bedeutung einer Antithese im griechischen Denken des 5 . Jahrhunderts. Basel: Schweitz. Beitr. Z. Altert. Wiss., 1945. (Versão de Mauro Engelmann). 
HIPPOCRATE. Oeuvres complètes d'Hippocrate. Traduction, introduction et notes philologiques par Émile Littré. Paris: Academie Royale de Médecine, tomo I, 1839; tomo II, 1840; tomo IV, 1844; tomo VI, 1849; tomo VII, 1851; tomo VIII, 1853; tomo IX, 1861a; tomo X, 1861b.

HIPPOCRATES. Hippocrates with a translation by W. H. S. Jones and E. T. Withington. London/Cambridge: Loeb Classical Library, 1923-92.

JOLY, Robert. Le niveau de la science hippocratique. Paris : Les Belles Lettres, 1966.

. Platon, Phèdre et Hippocrate : vingt ans aprés.

In La collection hippocratique et son rôle dans la médecine: Colloque Hipocratique de Strasbourg. Leiden: E. J. Brill, 1975. p. 407-21.

JOUANNA, J. Hippocrate. Paris: Fayard, 1992.

. Greek medicine from Hippocrates to Galen. Leiden/ Boston: Brill, 2012.

. L'Interpretation des reves et la theorie micromacro-cosmique dans le traité hippocratique $\mathrm{Du}$ regime: semiotique et mimesis. In: FISCHER, K.-D., NICKEL, D., POTTER, P. (ed.). Text and Tradition: Studies in Ancient Medicine and Its Transmission Presented to Jutta Kollesch. Leiden: Brill, 1998. p. 161-74.

1988.

. Ippocrate e il sacro. Koinônia, v. 12, p.91-113,

. La naissance de l'art médical occidental. In: GRMEK, Mirko D. (org.) Histoire de la pensée médicale en Occident: Antiquité et Moyen Âge. Paris: Seuil, 1995. p. 25-66.

Rhétorique et médecine dans la collection hippocratique: contribution à l'histoire de la rhétorique au Ve siècle. Revue des études grecques, v. 97, p.26-44, 1984.

. BOUDON, V. Remarques sur la place d'Hippocrate dans la pharmacologie de Galien. In DEBRU, A. Galen on Pharmacology: Philosophy, History and Medicine. Leiden: Brill, 1997. p. 213-234. 
LASKARIS, J. The art is long: On the Sacred Disease and the Scientific Tradition. Leiden: Brill, 2002.

LASSERRE, F. (ed.) Formes de pensée dans la collection hippocratique. Geneve, 1983.

LÉVI-STRAUSS, C. Estruturas elementares do parentesco. Petrópolis: Vozes, 1982.

PIGEAUD, Jackie. Folie et cures de la folie chez les médecins de l'antiquité gréco-romaine: la manie. Paris: Les Belles Lettres, 1987.

Nature et culture dans l'Éthique a Nicomaque d'Aristote. Conferência proferida na X Reunião da Sociedade Brasileira de Estudos Clássicos. São Paulo, 1997. [Publicação restrita ao Congresso]

LLOYD, G. Origines et développement de la science grecque. Paris: Flammarion, 1990.

PLATON. Phedre. Paris: Les Belles Lettres, 1985.

ROTHWELL, K. Nature, culture and the origins of Greek comedy. Cambridge: Cambridge University Press, 2006.

THIVEL, A. \& ZUCKER, A. (eds.). Le normal et le pathologique dans la Collection hippocratique. Nice: 2002.

THOMAS, R. Prose Performance Texts: Epideixis and Written Publication in the Late Fifth and Early Fourth Centuries. In: YUNIS, Harvey (ed.). Written Texts and the Rise of Literate Culture in Ancient Greece. Cambridge: CUP, 2003. p.162-188.

THUCYDIDE. La Guerre du Péloponnèse. Livre II. Paris: Les Belles Lettres, 1962.

VAN DER EIJK, P. (ed.) Hippocrates in context. Leiden: Brill, 2005.

. Towards a rhetoric of ancient scientific discourse.

In: BAKKER, E. J. (ed.). Grammar as interpretation: Greek literature and its linguistic contexts. Leiden: Brill, 1997. p.77-129. 